\title{
Alkohol - är det något för ekonomer?
}

\section{FREDRIK BERGGREN OCH BJÖRN LINDGREN}

\begin{abstract}
Artikeln gör en översiktlig genomgång av ekonomisk vetenskaps applicering på bruket av alkohol. En indelning görs i traditionell efterfrågeanalys, rationellt beroende, skatter och andra alkoholpolitiska ätgärder, samhällsekonomiska kostnader samt ekonomiska utvärderingar. Avslut ningsvis kommenteras det bidrag ekonomisk analys kan ge till policybeslut samt diskuteras framtida perspektiv för den ekonomiska forskningen inom detta område.
\end{abstract}

Konsumtionen av öl, vin och andra alkoholhaltiga drycker är för många människor en form av stimulans och ett naturligt inslag $i$ det sociala livet. Samtidigt är konsumtionen av alkohol både riskfylld och beroendeframkallande. Kan ekonomisk vetenskap ge ett bidrag till förståelsen av alkoholrelaterade beteenden och vara behjälplig när det gäller att formulera en alkoholpolitik? Det är de frågor vi skall försöka besvara $\mathrm{i}$ den här översikten; för en fylligare översikt hänvisas till Berggren \& Lindgren (1995).

Fredrik Berggren är doktorand i hälsoekonomi och skriver på en avhandling om alkoholkonsumtion $\mathrm{i}$ Sverige. Björn Lindgren är professor i hälsoekonomi och leder ett forskningsprojekt om samhällsekonomiska aspekter på alkoholbruk med stöd av Folkhälsoinstitutet. Båda är knutna till de nationalekonomiska och samhällsmedicinska institutionerna vid Lunds universitet.
För de flesta människor är marknader och pengar de studieobjekt som ekonomer hänger sig åt. Vi skall villigt erkänna att för många ekonomer är detta ett lika naturligt synsätt som det är för lekmannen. Men det finns en tradition inom nationalekonomin att studera beteenden, valsituationer och beslut som inte nödvändigtvis förutsätter att det finns en marknad där varan eller tjänsten kan säljas och köpas. Jeremy Bentham studerade exempelvis kriminellt beteende med hjälp av ekonomisk teori och analysmetod (Bentham, 1789). Thomas Malthus är känd för sina ekonomiska analyser av villkoren för hur snabbt en befolkning växer (Malthus, 1803). Sedan dess har många andra fenomen som inte förutsätter existensen av marknader analyserats av nationalekonomerna; en eminent företrädare 
för denna tradition är nobelpristagaren $\mathrm{i}$ ekonomisk vetenskap 1992, Gary Becker, som i ett antal arbeten studerat kriminalitet, giftermål, drogberoende m.m. (Becker, 1968, 1976, Becker \& Murphy, 1988). Det är uppenbart att nationalekonomerna själva upplever att de har ett budskap att förmedla, även när de analyserar vad man skulle kunna kalla icke-ekonomiska fenomen. Det gäller även konsumtionen av alkohol. Rubrikens retoriska fråga kan alltså besvaras jakande redan här.

\section{Positiv och normativ ekonomisk teori}

Ekonomisk analys utgår från att resurserna är knappa: råvaror, energi, maskiner och verktyg samt människors kunskap, erfarenheter och tid räcker inte till för att åstadkomma allt vad vi människor skulle vilja ha. All ekonomisk analys utgår också från att det finns flera alternativ att använda resurserna till. Vi måste alltså välja hur vi skall utnyttja de begränsade resurser som står till buds. Nationalekonomerna skiljer vidare mellan positiv och normativ teori. En positiv ekonomisk teori är en ekonomisk teori som förklarar individernas beteende eller som förutsäger vad som kommer att hända om någon av de faktorer som påverkar individens beteende ändras: priser, inkomster, information om risker, behandlingsmöjligheter för alkoholskador etc. Det bör observeras att det inte är enskilda individer som studeras i första hand, utan intresset gäller främst de samlade effekterna på alkoholkonsumtionen för grupper av individer. En normativ ekonomisk teori utgår från en bestämd etisk princip. På basis av denna av- görs om ett tillstånd är bättre (eller förväntas vara bättre) än något annat och därför kan rekommenderas. Den normativa analysen ger slutsatser som föreskriver eller rekommenderar ett visst beteende eller en viss åtgärd.

Den ekonomiska välfärdsteorin är en normativ teori som bygger på principen att ett tillstånd är bättre än ett annat tillstånd för en grupp av individer, om åtminstone en av individerna upplever sig fả det bättre utan att någon annan får det sämre. Efter den italienske sociologen och nationalekonomen Vilfredo Pareto kallas principen paretoprincipen. Ett tillstånd som är sådant att det är omöjligt att finna något annat tillstånd som leder till att någon får det bättre utan att någon annan samtidigt får det sämre kallas ett paretooptimum eller, ofta, ett samhällsekonomiskt effektivt tillstånd. Det framgår av det sagda att den ekonomiska välfärdsteorin har starkt individualistiska utgångspunkter; den enskilde individen anses vara bäst skickad att bedöma sin egen nytta av sin konsumtion, och en grupp av individer kan per definition aldrig få det bättre om en enda individ upplever att hon skulle få det sämre i alla andra tänkbara situationer.

Det kan visas att en väl fungerande marknadsekonomi leder till att ett samhällsekonomiskt effektivt tillstånd etableras; för en elementär framställning se exempelvis Bohm (1972). Men det finns inte alltid förutsättningar för att marknaderna skall fungera på det sättet. Som marknadsmisslyckanden betraktas bl.a. företeelser som monopol, s.k. kollektiva varor och externa effekter. De senare är effekter på andra individers välfärd som inte fullt ut beaktas i en 
viss individs konsumtionsbeslut; ett exempel är den ökade risk man utsätter sina medtrafikanter för, om man själv skulle köra sin bil i starkt berusat tillstånd. De samhällsekonomiska effektivitetsförluster som marknadsmisslyckanden medför gör att det finns anledning att överväga offentliga ingrepp; man kan höja priset på alkoholhaltiga drycker för att minska konsumtionen och den vägen eventuellt också minska de risker som rattfylleriet medför för den berusades medtrafikanter; man kan lagstifta om straffpåföljd om bilförare kör i berusat tillstånd etc. Ingrepp kan dock endast försvaras av samhällsekonomiska effektivitetsskäl, om de kan förväntas göra större nytta än skada. Ingreppen kräver administrativa resurser, och de kan i övrigt vara kostsamma genom negativa återverkningar inom andra områden av ekonomin med effektivitetsförluster som följd. Varken marknaden eller politiken är någonsin perfekt fungerande; lika väl som det existerar marknadsmisslyckanden, förekommer misslyckanden $i$ det politiska beslutsfattandet (Tullock,1994).

Vår översikt börjar med efterfrågan och allra först redovisas erfarenheter från tilllämpningar av den traditionella efterfrågeanalysen. I denna bortses från alkoholens speciella egenskaper. Efterfrågan på alkoholhaltiga drycker analyseras som vilka andra varor eller tjänster som helst. Det är främst hur pris- och inkomstförändringar påverkar konsumtionen som undersöks. Därefter behandlas den moderna ekonomiska teorin för rationellt beroende. Ansatsen kan sägas vara att konsumtion av beroendeframkallande varor är ett konsumtionsval som berör även andra tidpunkter än den då den beroendeframkallande varan konsumeras. Det följande avsnittet behandlar skatter och andra alkoholpolitiska åtgärder. I det därpå följande avsnittet sker en genomgång av beräkningar som gjorts av samhällsekonomiska kostnader. Dessa beräkningar brukar alltid väcka uppmärksamhet; inte minst genom de ofattligt många miljarder som det ibland tycks vara tal om. Beräkningarna avser att visa vilka möjligheter att konsumera andra varor och tjänster som en befolkning går miste om till följd av alkoholkonsumtionen och dess negativa konsekvenser i form av sjukdom och skador. Så följer ett avsnitt om ekonomiska utvärderingar av behandling av personer med alkoholproblem. Syftet med ekonomiska utvärderingar är att bidra till beslutsunderlaget, när resursanvändningsbeslut skall fattas inom sektorer som saknar effektiva marknadssignaler.

Medan de fyra första avsnitten samtliga redovisar tillämpningar av positiv ekonomisk teori utgör avsnittet om ekonomiska utvärderingar exempel på en normativ ansats. Översikten avslutas med en kort kommentar om den ekonomiska forskningens policy-relevans samt en diskussion om perspektiven för den framtida ekonomiska forskningen inom detta område.

\section{Traditionell efterfrågeanalys}

I en efterfrågeanalys undersöks hur prisoch inkomstförändringar påverkar konsumtionen av en vara eller tjänst. Analysen kan även innefatta andra variabler av betydelse för efterfrågan. Det finns relativt gott om undersökningar av alkoholkonsumtionen i olika länder genomförda vid olika tidpunkter. Undersökningarnas relativa popularitet kan förmodligen förklaras med samhällets 
intresse för alkoholfrågor, goda empiriska data och varierande konsumtionsmöjligheter i olika länder. Även kravet på aktuellt beslutsunderlag kan motivera genomförandet av undersökningar. Den metodik som används ger nämligen goda möjligheter att analysera de förväntade effekterna av olika alkoholpolitiska åtgärder som syftar till att begränsa den totala konsumtionen. Resultaten från en efterfrågeanalys redovisas vanligen i form av elasticiteter. En elasticitet uttrycker hur känslig efterfrågan är för en förändring i någon av de variabler som ingår $\mathrm{i}$ undersökningen.

Egenpriselasticiteter kan sägas uttrycka med hur många procent den efterfrågade mängden av varan förändras vid en enprocentig förändring av priset på samma vara. Om egenpriselasticiteten är nära noll är varan att betrakta som prisokänslig och desto mindre (mer negativ) elasticiteten är desto priskänsligare är varan. Korspriselasticiteter uttrycker hur mycket den efterfrågade mängden av en vara förändras när priset på en annan vara förändras. Korspriselasticiteter tenderar att vara positiva, om varorna är substitut, och negativa, om de är komplement. Inkomstelasticiteten beskriver hur den efterfrågade mängden förändras vid en ökning i inkomsten. Om inkomstelasticiteten är större än 1 betraktas varan definitionsmässigt som en lyxvara. Är elasticiteten mindre än 1 är varan en nödvändig vara enligt ekonomisk terminologi.

Elasticiteter ger mått på hur efterfrågan på alkohol påverkas av en eller flera prisoch inkomstförändringar. Elasticiteterna kan således tas som utgångspunkt för att göra prediktioner rörande effekterna av alkoholpolitiska åtgärder, exempelvis vid en förändring av alkoholbeskattningen.

Av de analyser som har gjorts i Sverige beträffande efterfrågan på alkohol märks främst Malmquist (1953) för 1944 års nykterhetskommitté i SOU 1952:52, Sundström \& Ekström (1962) för hela den svenska dryckesmarknaden, Huitfeldt \& Jorner (1972) i SOU 1972:91 från Alkoholpolitiska utredningen samt Assarsson (1991). Assarssons artikel finns, i en delvis annorlunda version, även i SOU 1991:52 från Alkoholskatteutredningen. I Selvanathan (1991) analyseras efterfrågan för nio olika länder, däribland Sverige. Resultaten från beräkningar av elasticiteter i dessa undersökningar presenteras i Tabell 1. Undersökningarna följer generellt uppdelningen av alkoholhaltiga drycker i öl, vin och sprit; avvikelser förekommer dock. Enligt Tabell 1 är sprit att beteckna som en prisokänslig vara. Vidare pekar resultaten på att sprit är att betrakta som en nödvändig vara. Senaste undersökningsresultaten visar att efterfrågan på vin är relativt okänslig för prisförändringar. Inkomstelasticiteten förefaller minska över tiden, vilket skulle innebära att vin från att ha varit en lyxvara har blivit en nödvändig vara. Skattningar av elasticiteter för öl har inte givit några säkra resultat; de redovisas därför med försiktighet av författarna.

Selvanathans och Assarssons undersökningar innefattar även en analys av korspriselasticiteter. Korspriselasticiteterna är ganska låga som synes i Tabell 2 och Tabell 3. Tolkningen av Selvanathans låga korspriselasticiteter är att olika former av alkoholhaltiga drycker kan ersätta varandra, när prisförhållandena ändras; de är dock inte några goda substitut. Undantaget i de båda 
Tabell 1

Egenpriselasticiteter och inkomstelasticiteter frän undersökningar rörande Sverige

\begin{tabular}{|c|c|c|c|c|}
\hline Författare & Vara & $\begin{array}{l}\text { Egenpris- } \\
\text { elasticitet }\end{array}$ & $\begin{array}{l}\text { Inkomst- } \\
\text { elasticitet }\end{array}$ & $\begin{array}{l}\text { Genomsnittlig } \\
\text { försäljning i liter } \\
\text { ren alkohol per } \\
\text { invånare/år } \\
\text { CAN (1993) }\end{array}$ \\
\hline $\begin{array}{l}\text { Malmquist (1953) } \\
\text { 1923-1939 }\end{array}$ & $\begin{array}{l}\text { sprit } \\
\text { vin }\end{array}$ & $\begin{array}{l}-0,3 \\
-1,0\end{array}$ & $\begin{array}{l}0,3 \\
1,2\end{array}$ & $\begin{array}{l}2,2 \\
0,09\end{array}$ \\
\hline $\begin{array}{l}\text { Sundström \& } \\
\text { Ekström (1962) } \\
\text { 1931-1954 }\end{array}$ & $\begin{array}{l}\text { sprit } \\
\text { vin } \\
\text { sprit och vin } \\
\text { öl } \\
(1923-38)\end{array}$ & $\begin{array}{l}-0,3 \\
-1,6 \\
-0,4 \\
-1,56\end{array}$ & $\begin{array}{l}0,9 \\
2,0 \\
1,0 \\
0,35\end{array}$ & $\begin{array}{l}2,3 \\
0,14 \\
2,4\end{array}$ \\
\hline $\begin{array}{l}\text { Huitfeld \& Jorner } \\
\text { (1972) 1956-1968 }\end{array}$ & sprit och vin & $-1,0$ & 0,7 & 3,1 \\
\hline $\begin{array}{l}\text { Huitfeld \& Jorner } \\
\text { (1972) 1956-1968 }\end{array}$ & $\begin{array}{l}\text { sprit } \\
\text { vin }\end{array}$ & $\begin{array}{l}-1,2 \\
-0,7\end{array}$ & $\begin{array}{l}0,4 \\
0,9\end{array}$ & $\begin{array}{l}2,6 \\
0,55\end{array}$ \\
\hline $\begin{array}{l}\text { Huitfeld \& Jomer } \\
\text { (1972) 1956-1968 } \\
\text { * per invånare } 15 \mathrm{ar} \\
\text { och däröver }\end{array}$ & $\begin{array}{l}\text { brännvin } \\
\text { övrig sprit } \\
\text { starkvin } \\
\text { lättvin }\end{array}$ & $\begin{array}{l}-0,9 \\
-2,9 \\
-0,7 \\
-0,6\end{array}$ & $\begin{array}{l}0 \\
1,4 \\
0,2 \\
-\end{array}$ & $\begin{array}{l}2,4 * \\
0,9 * \\
0,3 * \\
0,3 *\end{array}$ \\
\hline $\begin{array}{l}\text { Selvanathan (1991) } \\
\text { 1960-1986 }\end{array}$ & $\begin{array}{l}\text { sprit } \\
\text { vin } \\
\text { öl }\end{array}$ & $\begin{array}{l}-0,22 \\
-0,87 \\
-0,35\end{array}$ & $\begin{array}{l}1,52 \\
0,48 \\
0,22\end{array}$ & $\begin{array}{l}2,6 \\
1,0 \\
1,6\end{array}$ \\
\hline $\begin{array}{l}\text { Assarsson (1991) } \\
\text { 1978-1988 }\end{array}$ & $\begin{array}{l}\text { sprit } \\
\text { vin } \\
\text { starköl } \\
\text { folköl }\end{array}$ & $\begin{array}{l}-0,9 \\
-0,8 \\
-1,7 \\
-1,5\end{array}$ & $\begin{array}{l}0,6 \\
0,4 \\
0,9 \\
1,4\end{array}$ & $\begin{array}{l}2,4 \\
1,3 \\
1,6 \\
-\end{array}$ \\
\hline
\end{tabular}

undersökningarna är att en höjning av priset på sprit ökar efterfrågan på vin relativt kraftigt. En höjning av priset på vin har däremot ingen större effekt på efterfrågan på sprit. I Assarssons undersökning är vissa korspriselasticiteter negativa. Detta pekar på att vissa alkoholhaltiga drycker skulle vara komplement. Förhållandet märks mest mel- lan öl och sprit, dvs. när priset på öl ökar, minskar även efterfrågan på sprit. Assarsson påvisar även en relativt stark substitutionseffekt från folköl till starköl. Den omvända effekten är som synes liten. Sammantaget ger korspriselasticiteterna vid handen att vinkonsumtionen påverkas starkt av priset på sprit och att starköls- 


\section{Tabell 2}

Egen- och korsprispriselasticiteter frän Selvanathan (1991)
\begin{tabular}{llll} 
Förändring i & & \\
efterfrågad mängd & Förändring i priset på & & \\
\hline & sprit & vin & öl \\
\hline sprit & $-0,22$ & 0,15 & 0,08 \\
vin & 0,54 & $-0,87$ & 0,34 \\
öl & 0,16 & 0,19 & $-0,35$
\end{tabular}

Tabell 3

Egen- och korsprispriselasticiteter frän Assarsson (1991)

Förändring i

efterfrågad mängd

Förändring i priset på

\begin{tabular}{lcccc}
\hline sprit & $-0,88$ & 0,16 & $-0,21$ & $-0,22$ \\
vin & 0,53 & $-0,89$ & $-0,19$ & -0.04 \\
starköl & 0,22 & 0,10 & $-1,29$ & 0,62 \\
folköl & $-0,34$ & $-0,10$ & 0,24 & $-1,17$
\end{tabular}

konsumtionen påverkas starkt av priset på folköl.

\section{Rationellt beroende}

I teoribildningen om rationellt beroende gör individen konsumtionsval som berör flera perioder, och konsumtionen i olika perioder är komplement till varandra. Sålunda kan den nuvarande konsumtionen av t.ex. alkohol ses som en funktion av både tidigare och framtida konsumtion. Vid en utvärdering av efterfrågeeffekter måste därför såväl tidigare, nuvarande som framtida konsumtion beaktas. Teorin om rationellt beroende behandlar rationalitet på ett sätt som är vanligt i ekonomisk teori, dvs. som förekomsten av en konsistent plan för att maximera individens preferenser över tiden. En stark böjelse för en vara kräver att förfluten kon- sumtion av varan har stor betydelse för den nuvarande konsumtionen. Att konsumtionen under olika tidsperioder är starka komplement till varandra medför att vissa långsiktiga jämvikter är instabila, beroende på att även små avvikelser därifrån antingen leder till kumulativt ökande konsumtion över tiden (alkoholism) eller ett snabbt fall i konsumtionen följt av avhållsamhet (absolutism). Individer som har starka böjelser hamnar ofta i situationer där omåttlig konsumtion av den beroendeframkallande varan sker, men av teorin följer att överdrivna böjelser lämpligen upphör genom ett abrupt upphörande av konsumtionen av den vara det finns en stark böjelse för. Beteendet förändras mer vid varaktiga än vid tillfälliga förändringar i priset på den beroendeframkallande varan. Ängslan, bekymmer och spänning påskyndar böjelsernas utveckling. 
Stigler \& Becker (1977) argumenterar för att traditionell ekonomisk analys är lika relevant när det gäller att analysera komplicerade beteenden som när det gäller enklare konsumtionsbeslut. Tesen är att allmänt spritt och/eller uthålligt mänskligt beteende kan förklaras utifrån existerande ekonomisk teoribildning. I A Theory of Rational Addiction konkretiserar Becker \& Murphy (1988) teoribildningen. Böjelser och beroende, även starka sådana, är vanligtvis rationella såtillvida att de är resultatet av en nyttomaximering med stabila preferenser. Prisnivån och dess utveckling, hur individen värdesätter framtiden och livsavgörande händelser påverkar sannolikheten att utveckla en rationell böjelse. Ett beteende som präglas av beroende eller böjelse för någonting innefattar förstärkning och tolerans. Med förstärkning menas att en större tidigare konsumtion av den beroendeframkallande varan, som alkohol eller tobak, ökar begäret för nuvarande konsumtion, medan tolerans varnar för att nyttan från en viss konsumtion är lägre när tidigare konsumtion är större.

Hur det förhåller sig med rationalitet och beroende kan testas direkt. Om konsumtion av en vara inte har någon beroendeframkallande effekt, då har tidigare konsumtion och pris ingen effekt på den nuvarande konsumtionen. Om konsumtionen av varan har beroendeframkallande effekt men individer beter sig kortsiktigt, kommer tidigare konsumtion och pris att ha positiv inverkan på den nuvarande konsumtionen, medan framtida konsumtion och pris inte har någon effekt. Hittills har rationellt beroende testats på cigarettrökning i bl.a. Chaulopka (1991), Becker et al (1991) och
Becker et al (1994) samt på alkohol i Waters \& Sloan (1995) och Grossman et al (1994). Resultaten har bekräftat huvuddragen av teoribildningen.

Waters \& Sloan (1995) ger stöd för teorin om rationellt beroende med data från USA. Tidigare och framtida konsumtion har ett positivt förhällande till den nuvarande konsumtionen. Även effekterna av priserna var signifikanta och överenstämde med teorin. Hushåll med låg inkomst var känsligare för prisförändringar. Individer med högre tidspreferenser var känsligare för nuvarande och tidigare priser samt tidigare konsumtion.

I Grossman et al (1994) används regelbundet insamlade data från individer under en period när dessa var 17 till 27 år gamla (paneldata från USA). Med dessa data undersöktes om unga vuxnas alkoholkonsumtion är känslig för priset på alkohol. Resultatet blev att dessa individers alkoholkonsumtion var beroendeframkallande i den meningen att ökningar i tidigare konsumtion hade signifikant positiv inverkan på den nuvarande konsumtionen. Den signifikanta positiva effekten av framtida konsumtion på nuvarande konsumtion är vidare konsistent med teorin om rationellt beroendebeteende. Den långsiktiga egenpriselasticiteten för öl är ungefär 60 procent högre än den kortsiktiga egenpriselasticiteten samt dubbelt så hög som den egenpriselasticitet som erhålls i en traditionell efterfrågeanalys, dvs. en analys som ignorerar beroendet. Resultaten antyder att konsumtionen av alkohol skulle vara något mindre beroendeframkallande än konsumtion av cigaretter.

Becker \& Murphy (1988) visar att, under i övrigt lika omständigheter, individer som 
beaktar nuet mycket tyngre än framtiden, m.a.o. har en hög tidspreferensfaktor, har större förutsättningar att utveckla starka böjelser. Inkomstnivån och tillfälliga stresssituationer ökar efterfrågan på varor med beroendeframkallande effekt. Prisnivån och dess utveckling påverkar sannolikheten att utveckla ett beroendeframkallande beteende. Becker et al (1991). påvisar att fattigare och yngre individer förefaller att lägga mindre vikt vid framtiden och att de tenderar att vara priskänsligare. Konsumtionen av många skadliga beroendeframkallande varor stimuleras av skilsmässor, arbetslöshet, dödsfall i familjen och andra stressande händelser. Om dessa händelser sänker den totala nyttan, medan de ökar marginalnyttan av beroendeframkallande varor, då har förändringar i livscykelförloppet samma effekt på konsumtionen som prisförändringar. Personer med samma preferenser och samma storlek på förmögenhet som möter samma priser kan således uppvisa olika grader av beroende om de har olika erfarenheter.

\section{Skatter och andra alkoholpolitiska åtgärder}

Beskattning av alkohol kan ske i olika perspektiv. Att förbättra statens finanser var länge det dominerande motivet i Sverige. Ur strikt statsfinansiell synvinkel är det fördelaktigt att beskatta varor eller tjänster som har en prisokänslig efterfrågan. I ett folkhälsoperspektiv däremot används beskattningen som instrument för att förändra konsumtionsmönstret. För att uppnå detta syfte krävs emellertid att varan eller tjänsten är priskänslig. Ju mer priskänslig, desto lättare nås målet. Av detta följer att priselasticiteter är viktiga mått för alkoholpolitiska åtgärder. Från en välfärdsekonomisk utgångspunkt krävs inte bara kunskap om elasticiteterna utan också om eventuella externa effekter och om de negativa återverkningarna av en ofullkomlig beskattning.

Den svenska alkoholpolitiken har till stor del varit inriktad på att sänka alkoholkonsumtionen genom restriktioner vid försäljning och genom prispolitik via skatter. Punktskattesatserna har varit utformade efter alkoholstyrka och pris på den försålda varan. Sedan den 1 juli 1992 punktbeskattas alkoholhaltiga drycker efter alkoholstyrkan utan direkt koppling till inköpspriset. Följden av att beskatta alkoholstyrkan är att kvalitetsviner och en del exklusiv importerad sprit relativt sett blivit billigare. Vidare har Sveriges medlemsskap i EU medfört en anpassning av den svenska alkoholpolitiken till EUs regelverk. Detta har bl.a. medfört att statens import-, export-, partihandels- och tillverkningsmonopol har slopats. Det gamla systemet ersätts med ett system med tillverknings- och partihandelstillstånd, till vilka följer rätten att importera och exportera. Vidare medför medlemskapet vissa förändringar i beskattningen av alkoholhaltiga drycker. Huvudlinjen från skatteomläggningen 1992, att det är alkoholstyrkan som beskattas, ligger dock kvar.

Vad förändringar i alkoholbeskattningen betyder för alkoholkonsumtionen kan analyseras i ekonomiska efterfrågemodeller som byggs på traditionell efterfrågeteori eller på teorin om rationellt beroende. Eftersom detaljhandelsledet (utbudssidan) i Sverige är monopoliserat, kan en simulering genom- 
föras med en modell enbart baserad på efterfrågan. I Assarsson (1991) görs en simulering av hur en ändring av skattepolitiken med oförändrat totalpris på alkohol skulle påverka totalkonsumtionen. Totalpriset på alkohol hålls alltså konstant. Detta görs genom att betrakta en prisökning för varje varugrupp: sprit, vin, starköl och folköl. När priset höjs på en varugrupp sänks priset på de andra varugrupperna. Storleken på prisökningen motsvaras av en enprocentig prisökning på folköl. En prisökning av en varugrupp medför alltså en prissänkning av de andra varugrupperna för att hålla totalpriset på alkohol konstant. I Tabell 4 redovisas de fyra olika alternativen där enbart den varugrupp för vilket priset höjs redovisas. Storleken på prisförändringarna modelleras av hur stor budgetandel varje varugrupp har av konsumtionen. Den procentuella prisökningen resulterade i för sprit 4,8 procent, vin 2,3 procent, starköl 2,3 procent och folköl 1 procent. Prisminskningarna för respektive varugrupp var en tredjedel av dessa siffror. Om målsättningen är att reducera den totala alkoholkonsumtionen, ger denna analys resultatet att en höjning av priset på sprit ger störst kortsiktig effekt, medan en höjning av priset på starköl ger störst långsiktig effekt. Den långsiktiga effekten nås efter ungefär två år. En prishöjning av vin eller folköl resulterar i en ökning av den totala konsumtionen. Den allra största ökningen fås vid en höjning av priset på folköl.

Konsumtionsmöjligheterna av alkohol är på olika sätt reglerad. Det som regleras kan vara t.ex. antalet försäljningsställen, utskänkningstillstånd, på viken plats alkohol får drickas, hur reklamen får se ut och vilken ålder som krävs för inköp respektive konsumtion. I Ornstein \& Hanssens (1985) undersöks konsumtionen av öl och sprit ( ej vin, eftersom data saknades) i USA som beroende av tre grupper av variabler, ekonomiska, sociodemografiska och reglerande. De reglerande/lagstiftande variablerna för alkohol kan delas in i tre grupper: (a) ekonomisk lagstiftning för att ge skatteintäkter och/eller för att skydda producenter, (b) försök att kontrollera de sociala kostnaderna av överkonsumtion av alkohol och (c) försök att hindra olaglig tillverkning av alkohol och

\section{Tabell 4}

Effekten på den totala alkoholkonsumtionen genom förändring av den statliga prispolitiken. Simuleringarna är baserade på förändringar i relativpriser med konstant totalpris på alkohol. Storleken på prisökningarna motsvarar en enprocentig prisökning på folköl.

Prisförändring i \%

\% förändring av

totalkonsumtionen:

kort sikt

lång sikt

\begin{tabular}{llll} 
sprit & vin & starköl & folköl \\
\hline$+4,8$ & $+2,3$ & $+2,3$ & $+1,0$
\end{tabular}


otillbörlig marknadsföring. Analysen visar att konsumtionen av öl och sprit svarar på olika sätt på förändringar i ekonomiska, sociodemografiska och reglerande variabler. Konsumtionsskillnader per capita i olika stater förklarades främst av skillnader i pris och inkomst och mindre av skillnader i reglering och lagstiftning. Lagstiftning som påverkar priset har följaktligen störst inverkan. Beträffande öl var den yngre populationen påverkbar när det gällde regleringar. Konsumtionen av sprit var priskänsligare än konsumtionen av öl. I Godfrey (1988) görs en ekonometrisk analys med priser, inkomst, reklam och försäljningstillstånd som förklarande variabler. Modellen skattades med data från Storbritannien för tidsperioden 1956-1980 med intentionen att undersöka betydelsen av antalet försäljningstillstånd för alkohol för efterfrågan på alkohol. Godfreys slutsats är att effekten av antalet försäljningstillstånd och efterfrågan på alkohol beror på de antaganden om förhållandena mellan efterfrågan och försäljningstillstånd samt på vilken nivå data för försäljningstillstånden aggregeras. Godfrey efterlyser ett fylligare och mer differentierat dataunderlag. Den potentiella betydelsen av antalet försäljningstillstånd får inte uteslutas vid formuleringen av politiska åtgärder.

I den ekonomiska litteraturen finns dessutom exempel på studier där ekonometriska ansatser tillämpats även på andra alkoholrelaterade frågeställningar. I Coock \& Tauchen (1982) undersöks variationerna av dödsfall i skrumplever (en vanlig diagnos på grund av hög alkoholkonsumtion) och variationer i per capita-konsumtion av sprit för tidsseriedata från 30 delstater i USA för perioden 1962-1977. De fann att skatt på sprit har en signifikant negativ påverkan på antalet dödsfall i skrumplever. Cook \& Moore (1993) undersöker med data från USA effekterna av ungdomars alkoholkonsumtion på antalet genomgångna skolår och sannolikheten för examen från någon högre utbildning. Resultatet visar att en hög alkoholkonsumtion under högstadiet minskar det genomsnittliga antalet utbildningsår efter högstadiet. Studenter som genomgick högstadiet i delstater med relativt hög skatt på öl och hög åldersgräns för inköp hade större sannolikhet att examineras från någon högre utbildning. Wilkinson (1987) utvecklar en modell för att simulera effekterna av olika åtgärder för att minska antalet alkoholrelaterade trafikolyckor med hjälp av data från olika delstater i USA 1976-1980. Simuleringarna indikerar att följande åtgärder är effektiva för att reducera antalet olyckor: strängare tillämpning av hastighetsgränser, en höjning av konsumtionsåldern till 21 år och tidigare stängning av utskänkningslokaler. I Manning et al (1995) redovisas resultat som indikerar att individer med ringa konsumtion och individer med stor konsumtion är mindre priskänsliga än måttlighetskonsumenter. Det kunde inte heller uteslutas att de allra största konsumenterna av alkohol är fullständigt prisokänsliga. I Manning et al (1989) beräknas den diskonterade livstidskostnad som rökare och alkoholkonsumenter lägger på andra individer genom kollektivt finansierade hälso- och sjukvårdförsäkringar, pensioner, livförsäkringar, bränder, trafikolyckor mm. Beräkningarna, som är genomförda med data från USA, visar att de amerikanska rökarna i stort sett betalar sina kostnader, 
medan de amerikanska alkoholkonsumenterna enbart täcker ungefär hälften av de kostnader de åsamkar andra individer. Det bör dock observeras att de amerikanska tobaks- och alkoholskatterna är lägre än de svenska och att skatter och försäkringssystem också har en annan utformning. Det bör också observeras att de kunskaper som finns kring alkoholens epidemiologi samt kausaliteten mellan alkohol och skador är fragmentariska. Än så länge finns det därför inte finns något entydigt sätt att avgöra storleken på en optimal beskattning från välfärdsteoretiska utgångspunkter (McDonnell \& Maynard, 1985b).

\section{Samhällsekonomisk kostnadsanalys}

Beräkningar av de samhällsekonomiska kostnaderna till följd av konsumtionen av alkohol avser att kvantifiera det totala värdet av de varor och tjänster samhället går miste om på grund av de oönskade effekter som bruket (alternativt missbruket) av alkohol ger upphov till. Det är således fråga om en alternativkostnad, och denna alternativkostnad kan begreppsmässigt delas upp i (1) direkta kostnader som uppstår på grund av att resurser som annars skulle ha använts till andra varor och tjänster i stället används till exempelvis hälso- och sjukvård, (2) indirekta kostnader som uppstår på grund av att resurser inte alls kan användas eller att de endast kan användas i begränsad utsträckning på grund av nedsatt eller utebliven arbetsförmåga. De indirekta kostnaderna brukar indelas i tre olika kategorier: tillfällig oförmåga att arbeta, bestående oförmåga att arbeta samt för tidig död.
Beräkningar av sjukdomars samhällsekonomiska kostnader enligt denna beskrivning kan sägas innebära att man gör en beräkning av vilka kostnader som finns ett bestämt år på grund av förekomsten (eller, med epidemiologiskt språkbruk, prevalensen) av sjukdom. Prevalensberäkningar tar inte hänsyn till när själva sjukdomen uppstår utan endast till när kostnaderna infaller. Gäller det kroniska sjukdomar eller vissa andra sjukdomar, såsom cancer, som kan ta lång tid att upptäcka eller diagnosticera, kan det dröja en avsevärd tid mellan det nyupptäckta fallet och sjukdomens konsekvenser i form av vårdkostnader och produktionsbortfall. Ibland ser man beräkningar som utgår från antalet nya fall (eller, med epidemiologiskt språkbruk, incidensen) av sjukdom. Incidensberäkningar utgår från det år då sjukdomen drabbar en individ och omfattar nuvärdet av förväntade nutida och framtida direkta och indirekta kostnader som en följd därav i princip alla kommande levnadsår. Med ekonomisk terminologi kan man säga att prevalens är ett beståndsbegrepp (ustocku), medan incidens är det motsvarande flödesbegreppet ( (flowu). Beräkningarna har inget normativt innehåll i sig; de kan dock utnyttjas som utgångspunkter för normativ analys. Som indikator på samhällets välfärdsförluster är beräkningarna av de samhällsekonomiska kostnaderna därför av föga värde. De koncentreras på endast en av de välfärdsskapande faktorerna, konsumtionen av varor och tjänster, och tar ingen hänsyn till den njutning som konsumenterna av alkoholhaltiga drycker upplever. För utförliga genomgångar av samhällsekonomisk kostnadsanalys se bl.a. Rice (1966), Hodgson (1983), Lindgren (1981) och (1990). 
Det finns ett begränsat antal beräkningar av samhällsekonomiska kostnader för alkohol. Ett urval av dessa presenteras i Tabell 5 . De olika analyserna avser att beräkna den samhällsekonomiska kostnaden av alkoholmissbruk (Berry \& Boland, 1977, Schifrin, 1983), av alkoholism och alkoholmissbruk (Holtermann \& Burchell, 1981, McDonnell \& Maynard, 1985a) och av alkoholkonsumtionen (Johnson, 1983 och 1991). I Tabell 5 redovisas produktionsförluster (indirekta kostnader), hälso- och sjukvårdskostnader och övrigt. Hälso- och sjukvårdskostnader inkluderar även socialvård och kriminalvård. I posten övrigt ingår kostnader för trafikolyckor, skadegörelse, egendomsskador, kostnader för förebyggande àtgärder och kostnader för polis och rättsväsende, alltså huvudsakligen direkta kostna- der. Den använda metodiken kan summariskt beskrivas som att författarna beräknar vilken andel av en viss kostnad som kan hänföras till bruket (alternativt missbruket) av alkohol. I de fall då kostnaderna inträffar vid olika tidpunkter sker en diskontering av kostnaderna till dess nuvärde. För de beräkningar som redovisas i Tabell 5 utgör de indirekta kostnaderna i form av produktionsförluster den avgjort största delen av de samhällsekonomiska kostnaderna. Produktionsförlusterna befinner sig $\mathrm{i}$ intervallet 49,6 till 86,5 procent av den totala samhällsekonomiska kostnaden. Den näst största posten, hälso- och sjukvårdskostnader, varierar mellan 5,9 och 27,3 procent. Variationen av resultaten kan delvis ha sin förklaring i skillnader i mätmetoder och sätt att hantera mätproblem. Klart är att avgränsningar

\begin{tabular}{|c|c|c|c|c|c|c|}
\hline Land/år & $\begin{array}{l}\text { Sverige } \\
1981\end{array}$ & $\begin{array}{l}\text { Sverige } \\
1988\end{array}$ & $\begin{array}{l}\text { USA } \\
1971\end{array}$ & $\begin{array}{l}\text { USA } \\
1979\end{array}$ & $\begin{array}{l}\text { England och } \\
\text { Wales, } \\
1977 / 1978\end{array}$ & $\begin{array}{l}\text { England och } \\
\text { Wales, } \\
\text { 1983 }\end{array}$ \\
\hline Författare & $\begin{array}{l}\text { Johnson } \\
\text { (1983) }\end{array}$ & $\begin{array}{l}\text { Johnson } \\
\text { (1991) }\end{array}$ & $\begin{array}{l}\text { Berry \& } \\
\text { Boland } \\
(1977)\end{array}$ & $\begin{array}{l}\text { Schifrin } \\
(1983)\end{array}$ & $\begin{array}{l}\text { Holtermann } \\
\text { \& Burchell } \\
(1981)^{* *}\end{array}$ & $\begin{array}{l}\text { Maynard \& } \\
\text { McDonell } \\
\text { (1985 a) }\end{array}$ \\
\hline $\begin{array}{l}\text { Produktions- } \\
\text { förlust }\end{array}$ & 49,6 & 54,9 & 47,3 & 68,4 & 82,8 & 86,5 \\
\hline $\begin{array}{l}\text { Hälso- och } \\
\text { sjukvård }\end{array}$ & 27,3 & 16,9 & 26,4 & 18,1 & 8,1 & 5,9 \\
\hline Övrigt & $23,1 *$ & $28,2 *$ & 26,3 & 13,6 & 9,1 & 7,5 \\
\hline Totalt & 100 & 100 & 100 & 100 & 100 & 100 \\
\hline
\end{tabular}

Berggren \& Lindgren - Alkohol är det något för ekonomer? 
och metoder för att kvantifiera data behöver förbättras för att ge robustare resultat. För att ge möjlighet till såväl intertemporala som internationella jämförelser krävs ett konsistent användande av en enhetlig metodik.

\section{Ekonomiska utvärderingar}

Samhällsekonomisk utvärdering av behandling av personer med alkoholproblem syftar till att kunna hantera resursfördelningen till och inom alkoholvården så att ett effektivt resursutnyttjande uppnås. Samhällsekonomiska utvärderingar är hjälpmedel som ekonomer utvecklat för att bistå beslutsfattarna på områden där marknadssignaler inte ger tillräcklig vägledning eller där verksamheten bedrivs med politiskt-administrativa beslut. För att kunna vara till hjälp i beslutsfattandet måste en samhällsekonomisk utvärdering göras före beslutet att genomföra en viss verksamhet eller inte. För ekonomiska utvärderingar inom hälso- och sjukvården eller andra preventiva, behandlande eller rehabiliterande program har det blivit praxis att skilja mellan fyra olika typer av metoder för utvärdering: kostnadsanalys, cost-effectiveness-analys, cost-utility-analys och cost-benefit-analys (Drummond et al, 1987).

Kostnadsanalys används när olika alternativ inte skiljer sig åt på något signifikant sätt beträffande hälsoeffekterna. Analysen syftar till att identifiera det minst kostsamma alternativet. En viktig ingrediens $i$ kostnadsanalysen kan vara att se hur kostnaderna fördelas, t.ex. mellan sjukvårdshuvudman och patient, i de olika alternativen. En kostnadsanalys bör innehålla något bevis på att resultatet från de olika alternativen inte skiljer sig åt eller är oviktigt. Costeffectiveness-analyser mäter resultatet av insatta resurser i någon gemensam enhet. De olika alternativen har kanske olika kostnader och uppfyller målet för projektet eller planen olika. Det är då inte rimligt att välja det projekt eller program som ger den lägsta kostnaden utan att beakta resultatet. I costeffectiveness-analyser jämförs oftast kostnader per vunnet levnadsår eller antalet vunna levnadsår per 100000 kronor. Noterbart är att denna metod gör att man kan jämföra vitt skilda åtgärder, så länge som man kan ange resultatet från dessa åtgärder som vunna levnadsår eller med hjälp av någon annan accepterad gemensam enhet. Metoden är dock ej lämplig för program och projekt som har flera effekter, exempelvis för ett program eller projekt som minskar både sjuklighet och dödlighet. För att utvärdera multipeleffekter finns andra metoder. I en cost-utility-analys mäts resultatet i s.k. kvalitetsjusterade levnadsår (QALY's, quality-adjusted life-years), varvid endast år som ger maximal hälsa tilldelas vikten ett. Cost-utility-analys är lämplig att använda när ett projekt inte bara påverkar livets längd utan också dess innehåll. För en genomgång av hälsoindex och dess användning vid ekonomiska utvärderingar, se Brooks (1995).

Cost-benefit-analys är den i princip mest omfattande undersökningsmetoden. Värdet av resultatet av resursanvändningen sammanfattas i monetära enheter, företrädesvis som betalningsvilja för projektet. Eftersom både kostnader och intäkter uttrycks i samma måttenheter som vid bedömningar av resursanvändningen inom helt andra om- 
råden, ger denna analysteknik teoretiska möjligheter att analysera vitt skilda frågeställningar. Den renodlade cost-benefit-analysen baseras på den ekonomiska välfärdsteorin, dess individualistiska ansats och den innebörd som välfärdsteorin ger begreppet samhällsekonomisk effektivitet.

Behandling av alkoholskador kan ge upphov till många olika effekter: förbättrade möjligheter att sköta ett jobb, ökad social funktionsduglighet, minskad kriminell aktivitet samt förbättrad psykologisk och fysisk hälsa för både individen och dennes familj. Trots detta har de flesta utvärderingar använt en starkt begränsad metod. Resultat har mätts i termer som konsumtion av alkohol eller avhållsamhet från alkohol. Om avhållsamhet har en hög korrelationsgrad med hälsa och livskvalitet är det ett relevant mått. Om inte, behövs ett vidare mått vid den samhällsekonomiska utvärderingen.

Flertalet av de tillgängliga utvärderingarna är kostnadsuppföljningar. Det finns vidare ett mindre antal tillgängliga cost-benefitoch cost-effectiveness-analyser. Dålig information om kostnader och resultat för olika behandlingar medför brister i utvärderingarna. Även i övrigt uppvisar de tillgängliga undersökningarna stora brister, om de bedöms enligt de kriterier som anges av Drummond et al (1987). Det finns visserligen en ansenlig mängd undersökningar som påvisar att behandlingsformer med låga kostnader kan ge lika goda behandlingsresultat som dyra behandlingsmetoder för många individer med alkoholproblem. Vid en differentiering efter grad av alkoholisering och social situation är resultatet inte lika entydigt. Tyngdpunkten bör enligt huvuddelen av de genomförda undersökning- arna ligga på annan vård än inläggning. Några centrala referenser när det gäller samhällsekonomisk utvärdering av behandling av alkoholproblem är Jones \& Vischi (1979), Holder (1987), Holder et al (1991) och Godfrey (1992).

\section{Avslutande kommentar}

Vår översikt har visat hur ekonomisk teori och analys kan tillämpas på bruket av alkohol. Utbudet av alkohol har däremot inte behandlats. Det förhåller sig nämligen så att utbudssidan av alkohol hittills inte verkar ha fått samma uppmärksamhet.

Vilka slutsatser kan dras vad gäller policy-relevans respektive framtida forskning om bruket av alkohol?

På grund av alkoholens beroendeframkallande egenskaper är det lämpligt att använda modeller för efterfrågeanalys som beaktar beroendeeffekter. Efterfrågeanalysen ger möjligheter att göra prediktioner av effekterna av olika policybeslut. Pris och beskattning påverkar efterfrågan, sannolikt olika för olika grupper av människor. Även regleringar och deras effekter kan studeras i ekonometriska modeller.

Det vore önskvärt om fler studier av rationellt beroende kunde göras i andra länder än USA. Möjligheterna att kunna testa teoribildningen om rationellt beroende på svenska förhållanden förefaller dock hittills vara begränsade. För att fullt ut kunna utnyttja konsekvenser och förutsägelser från teorin om rationellt beroende behövs paneldata på mikronivå. Tyvärr har vi inte tillgång till den typen av data för närvarande.

Väl genomförda beräkningar av de samhällsekonomiska kostnaderna till följd av 
alkohol(miss)bruk kan användas för att följa och jämföra resultatet av preventiva insatser, förändrade alkoholvanor och förbättrade behandlingsstrategier. Även om beräkningarna begränsar sig till kostnaderna är det ändå värdefull delinformation. För att bli ett användbart redskap måste dessa beräkningar emellertid få en väl definierad grundstruktur och genomföras med regelbundenhet. En väl definierad grundstruktur behövs för att kunna tillgodogöra sig delberäkningar av de totala samhällsekonomiska kostnaderna såsom sjukhuskostnadernas utveckling i förhållande till samtliga kostnader. En regelbundenhet över tiden behövs för att kunna analysera och åtgärda eventuella förändringar för de olika kostnadsposterna. I framtiden måste tilllämpningarna av metodiken för att genomföra samhällsekonomiska kostnadsberäkningar bli enhetligare än hittills. Annars kommer de helt att förlora sin trovärdighet.

Ekonomiska utvärderingar är hjälpmedel som ekonomer utvecklat för att bistå beslutsfattare på områden där marknaderna anses fungera mindre bra eller där de av olika skäl är helt ersatta av politiskt-administrativa beslut, dvs. i den offentliga sektorn. Utvärderingarna skall ersätta marknadssignaler och vara behjälpliga vid allokeringsbeslut. Utvärderingarna förutsätter implicit att befintliga resurser skall användas effektivt. Andra hänsyn kan vara fördelningspolitik och sysselsättningspolitik. En svårighet med att utvärdera vård av alkoholrelaterade problem är att det inte råder konsensus om hur effekten av vården skall hanteras för att överensstämma med existerande utvärderingsredskap.

Svenska ekonomer har hittills inte engagerats (eller engagerat sig) i någon större utsträckning om bruket av alkohol (Folkhälsoinstitutet, 1995). Det är synd, tycker vi. Den ekonomiska vetenskapen omfattar en rad olika analytiska redskap som är applicerbara på alkoholrelaterade frågeställningar och som kan ge användbara resultat av policykaraktär. Ett ökat flervetenskapligt samarbete skulle dessutom kunna medföra en stabilare och mer omfattande kunskapsbas.

Den ekonomiska alkoholforskningen rymmer även en kvalificerad inomvetenskaplig utmaning. Bruket av alkohol, tobak och droger och användningen av läkemedel av typ Prosac ställer postulatet om individens rationalitet på sin spets. Var går egentligen gränsen för den ekonomiska teorin om individens beteende - en hörnsten i den nationalekonomiska teoribildningen - och var tar neurobiologin över? 


\section{Referenslista}

Assarsson, B. (1991): Alcohol pricing policy and the demand for alcohol in Sweden 1978-1988, Working Paper 1991:19, Department of Economics, Uppsala University.

Becker, G.S. (1968): Crime and punishment: An economic approach, Journal of Political Econo$m y, 76,169-217$.

Becker, G.S. (1976) The Economic Approach to Human Behavior, The University of Chigaco Press.

Becker, G.S. \& Murphy, K. (1988): A theory of rational addiction, Journal of Political Economy, 96, 675-701.

Becker, G.S., Grossman, M. \& Murphy, K. (1991): Rational addiction and the effect of price on consumption, American Economic Review, 81:2, 237-241.

Becker, G.S., Grossman, M. \& Murphy, K. (1994): An empirical analysis of cigarette addiction, American Economic Review, 84:3, 396-418.

Bentham, J. (1789) „Introduction to the Principles of Morals and Legislation", i Stephan, L., (1950) The English Utilitarians, vol I,: The London School of Economics and Political Science.

Berggren, F. \& Lindgren, B. (1995): Bruket av alkohol - en översikt av den ekonomiska forskningen, Studier i hälsoekonomi 11, Institutionen för klinisk samhällsmedicin (Malmö) och Institutet för Ekonomisk Forskning, Lunds universitet.

Berry, R.E. \& Boland, J.P. (1977) The economic cost of alcohol abuse, New York, Free Press.

Bohm, P. (1972) Samhällsekonomisk effektivitet, Studieförbundet Näringsliv och Samhälle, Stockholm

Brooks, R.G. (1995) Health Status Measurement. A Perspective on Change, Macmillan, London.

CAN (1993): Rapport 93, Alkohol- och narkotikautvecklingen i Sverige, Rapport-serie nr 26, Centralförbundet för alkohol- och narkotikaupplysning (CAN) och Folkhälsoinstitutet.

Chaloupka, F.J. (1991): Rational addictive behavior and cigarette smoking, Journal of Political Economy, 99, 722-742.

Cook, P.J. \& Tauchen, G. (1982): The effect of liquor taxes on heavy drinking, Bell Journal of Economics, 13, 379-390.
Cook, P.J. \& Moore, J.M. (1993): Drinking and schooling, Journal of Health Economics, 12, 411429.

Drummond, M.F., Stoddart, G.L. \& Torrance, G.W. (1987) Methods for the Economic Evaluation of Health Care Programmes, Oxford Medical Publications, Oxford University Press.

Folkhälsoinstitutet (1995): Forskning om alkohol för individ och samhälle. Rapport från Alkoholforskningsutredningen.

Godfrey, C. (1988): Licensing and demand for alcohol, Applied Economics, 20, 1541-1558.

Godfrey, C. (1992): The Cost-effectiveness of alcohol services: Lessons for contracting?, Yartic Occasional Paper 2, Centre for Health Economics, University of York.

Grossman, M., Chaloupka, F. \& Sirtalan I. (1994): An empirical analysis of alcohol addiction: Results from the monitoring the future panels, $\mathrm{Pa}$ per presented at the annual meetings of the Allied Social Science Associations in Washington D.C., 6-8 januari 1995.

Hodgson, T.A. (1983) „The state of the arts of costof-illness estimates i i Scheffler, R.M. \& Rossiter, L.F., red,: Advances in Health Economics and Health Services Research. Volume 4. JAI Press Inc, Greenwich, Connecticut.

Holder, H.D. (1987): Alcoholism Treatment and Potential Health Care Cost Saving, Medical Care, 25:1, 52-71.

Holder, H.D., Longabaugh, R., Miller, W.R. \& Rubonis, A.V.(1991): The cost effectiveness of treatment for alcoholism: A first approximation, Journal of Studies on Alcohol, 52:6, 517540.

Holtermann, S. \& Burchell, A. (1981): The Costs of Alcohol Misuse, Goverment Economic Service Working Paper no 37, DHSS, London.

Huitfeldt, B. \& Jorner, U. (1972): Efterfrågan på rusdrycker i Sverige, En ekonometrisk undersökning av konsumtionens utveckling efter motbokens avskaffande, SOU 1972:91, Rapport från Alkoholpolitiska utredningen (APU).

Johnson, A. (1983) Femtio miljarder kostar supen, Sober, Stockholm. 
Johnson, A. (1991) Hundra miljarder kostar supen, Sober, Stockholm.

Jones, K.R. \& Vishi T.R. (1979): Impact of alcohol, drug abuse and mental health treatment on medical care utalization, Medical Care, 17:12, $1-82$, supplement.

Lindgren, B. (1981) Costs of illness in Sweden 19641975, Lund Economic Studies 24, Doktorsavhandling, Nationalekonomiska institutionen, Lunds universitet.

Lindgren, B. (1990) "The economic impact of illness» i Abshagen U. \& Münnich, F.E., red,: Costs of Illness and Benefits of Drug Treatment, 12-20, Zuckschwerdt, München.

Malmquist, S. (1953) "Statistisk analys av spritdrycksutminuteringen i Sverige« i $S O U$ 1952:52, 160-191.

Malthus, T.R. (1803) An Essay on the Principle of Population, ed. James P. (1989) vol. 1, Cambridge Univiversity Press.

Manning, W.G., Keeler, E.B., Newhouse, J.P., Sloss, E.M. \& Wasserman, J. (1989): The taxes of sin: Do smokers and drinkers pay their way, JAMA, 261:11, 1604-1609.

Manning, W.G., Blumberg, L. \& Moulton, L.H. (1995): The demand for alcohol: The differential response to price, Journal of Health Economics, 14, 123-148.

McDonnell, R. \& Maynard, A. (1985a): The Costs of Alcohol Misuse, British Journal of Addiction, 80, 27-35.

McDonnell, R. \& Maynard, A (1985b): Counting the cost of alcohol: gaps in epidemiological knowledge, Community Medicine, 7, 4-17.

Ornstein, S.I. \& Hanssens, D.M. (1985): Alcohol

Control Laws and the Consumption of Distilled Spirits and Beer, Journal of Consumer Research, 12, 200-213.

Rice, D.P. (1966): Estimating the Cost of Illness, Health Economics Series No. 6, Public Health Service, US Goverment Printing Office, Washington DC.

Schifrin, L.G. (1983) "Societal costs of alcohol abuse in the United States: an updating " i Grant, M.,Plant, M. \& Williams, A., red,: Economics and Alcohol consumption and controls, Croom Helm, London.

Selvanathan, E. A. (1991): Cross-country alcohol consumption comparsion: an application of the Rotterdam demand system, Applied Economics, 23, 1613-1622.

SOU 1991:52: Alkoholbeskattningen, Betänkande från alkoholskatteutredningen.

Stigler, G.J. \& Becker, G.S. (1977): De Gustibus Non Est Disputandum, American Economic Review, 67, 76-90.

Sundström, Å. \& Ekström, J. (1962) Dryckeskonsumtionen i Sverige, Industrins Utredningsinstitut, Stockholm.

Tullock, G. (1994) Den politiska marknaden, AB Timbro, Oskarshamn.

Waters, T.M. \& Sloan F.A. (1995): Why do people drink? Tests of the rational addiction model, Applied Economics, 27, 727-736.

Wilkinson, J.T. (1987): Reducing Drunken Driving: Which Polices Are Most Effective?, Southern Economic Journal, 54:2, 322-334. 


\section{Summary}

\section{Alcohol - something for the economist?}

This article makes a review of the application of economics to the use of alcoholic beverages and describes how economics can be a tool for policy-making on alcohol-related problems. The different economic approaches treated are: traditional demand, rational addiction, taxes and other policyrelated actions, social costs and economic appraisals. Traditional demand theory treats alcohol like any other good, without taking future aspects of current consumption into account. This sort of demand theory indicates a myopic behaviour of the individual decision to consume alcohol. The theory of rational addiction treats current alcohol consumption as a decision of past and future consumption together with past, current, and future prices. Support exists in the rational addiction literature for the notion that alcohol is an addictive good in the sense that past consumption affects current consumption. Furthermore, consumption of alcohol tends to be rational in the sense that future prices and consump- tion affect current consumption positively. Different aspects of regulation and policymaking are briefly reviewed. Calculations of the social cost of alcohol often get great attention. Calculations of the social cost from Sweden, USA, and England and Wales are compared. Economic appraisals of treatment of alcohol-related problems are reviewed, but are found not to reach a satisfactory scientific standard. The applications of economic theory to the use of alcoholic beverages have been rather rare in Sweden. A few demand analyses at the request of central government and an attempt to calculate the social costs of the use of alcohol have been undertaken. Economics could be of assistance to widen the knowledge about alcohol-related problems. The closing comments indicate how economics can contribute to the understanding of alcohol-related issues, and be a helpful tool in policy-making, as well as pointing to some aspects of future economic research. 